\title{
Detection and Evaluation of Surface Defects in Bridges by Terrestrial Laser Scanning
}

\author{
Ayman Elshehaby ${ }^{1}$, Khaled Zaky ${ }^{1}$, Farag Bastawy ${ }^{2}$ and Hany Abd Elmaksoud ${ }^{3}$ \\ ${ }^{1}$ Assistant Professor of Surveying, Dept. of Surveying, Shoubra Faculty of Engineering, Benha University, Cairo, Egypt. \\ ${ }^{2}$ Lecturer of Surveying, Dept. of Surveying, Shoubra Faculty of Engineering, Benha University, Cairo, Egypt. \\ ${ }^{3}$ University Teaching Assistant, Dept. of Civil Engineering, Thebes academy, Cairo, Egypt.
}

Correspondence Author: Hany Abd Elmaksoud, University Teaching Assistant, Dept. of Civil Engineering, Thebes academy, Cairo, Egypt. E-mail: eng_hany91@yahoo.com

Received date: 15 April 2018, Accepted date: 15 June 2018, Online date: 25 July 2018

Copyright: (c) 2018 Ayman Elshehaby et al. This is an open-access article distributed under the terms of the Creative Commons Attribution License, which permits unrestricted use, distribution, and reproduction in any medium, provided the original author and source are credited.

\begin{abstract}
There are some factors that may cause bridge damages such as the heavy traffic and aggressive environmental conditions. It's important to assess the current status of the bridge to decide on the future steps for rehabilitation. This is due to their impact on landscape where they are built to satisfy the public safety in bridge structural capacity. Despite, the actual bridge techniques demands hard works and lots of subjective visual analysis to decide the state of the bridge. Light Detection and Ranging (LiDAR), also named as Terrestrial Laser Scanning (TLS) is a remote sensing technique that could assist to minimize the variability of results and cover bigger areas, allowing for accurate determination of defects and precise allocation of appropriate funding. The main aim of this research is to develop an easy system to register laser remote sensing data of as-built model, with BrIM (Bridge Information Model) for constructed bridge and compare between them to detect the geometric discrepancies and defects. Mohamed Fawzy Bridge (which is located in Maadi Ring Road, Cairo, Egypt) has been selected as the scenery of this experimental investigation to approve this technique, focused on monitoring structural damages. The scanned data is used to evaluate the status of the selected bridge, its surface defects, vertical clearance, cracks length and width by using the basic software. This data is compared with its corresponding data extracted from the bridge design or drawing. The results of comparison indicate that the used equipment and technique achieved the required tasks with good accuracy.
\end{abstract}

Key words: 3D laser scanning, bridge clearance, Point cloud Registration, LiDAR, Terrestrial, Laser Scanning (TLS), Inspection, Surface Defects, Crack Measurements.

\section{INTRODUCTION}

Through years of hard use and shrinking maintenance funding, bridges infrastructure system has been rapidly deteriorating in a form of cracks, spalling, corrosion, and scaling. Additionally, errors and inaccuracies, which are mostly due to human interaction and challenging materials behaviors in different stages, are other issues that cause rework and costs as a consequence. All of these effects can reduce bridge's load carrying capacity and cause serious problems, such as closure or collapse. Delay in damage detection constitutes the cause of construction rework cost [Nahangi et al., 2014; Akinci et al., 2006; Arditi and Gunaydin, 1997]. Early detection of possible structural damage is critical. Despite, the actual bridge techniques may need hard works and lots of subjective visual analysis to observe the status of the bridge. It is difficult to obtain a reliable bridge condition assessment depending on the inspector consequently, to avoid larger interference and renovation costs, it must be always observing the construction developments [Ismaiel et al., 2013; Gairns, 2008]. Remote sensing techniques such as Light Detection and Ranging (LiDAR) is one of the current methods used for this purpose allowing for accurate determination of defects and precise allocation of appropriate funding. Laser scanning technique is the newest and reliably technology for object geometry recovery. Laser scanners take a large quantity of points for objects in a short time in order to deliver what is called "point cloud" [Abdelhafiz et al. 2014]. To obtain all faces and details for an object, it is required to take multiple scans from many different positions to create $3 \mathrm{~d}$ model of the object. TLS is a kind of range measurement method which has been utilized for collecting 3D geometric as-built information for reformation, engineering survey, structure geometric quantification and expansion works in commercial, industrial and heavy civil areas of construction. Most researches using laser scanners in structural assessment has focused on measuring structural deformation, estimating material loss, or finding surface defects, which can be employed in structural engineering such as complete drawings for an as-built structure or to assess the current dimensions of the as-built structure with its design [Abdelhafiz et al. 2009]. [Sedek et al. 2015] represented an automated advance to register laser remote sensing data of as-built model, with bridge information model for constructed bridge. The model is concluded to be accurate to monitor the construction processes. [Kim et al. 2013] suggested a procedure of progress measurement that requires a 4D BIM in harmony with a 3D point cloud taken by terrestrial laser scanning. This procedure has three stages: alignment of the as-built data with the as-planned model, matching of the as-built data to information in the BIM, and revision of the as-built status. That was to assist identification aspects of the as-built status that were inaccurate. [Tzedaki and Kamara et al. 2013] utilize laser scanning to gain better as-built BIM models. [Anil et al. 2013] utilized laser scanners to represent crack information on the surface of structures using a BIM approach. [Liu et al. 2012] presented an automated bridge clearance measurement method consisted on terrestrial scanning. [Akinci et al. 2012] used laser scanning with the aim of establish the as-built conditions of bridges for inspection purposes. [Wanqiu and Shen-En et al. 2011] demonstrated that terrestrial LiDAR can make useful metrics for bridge clearance problems, static deflection measurement, find surface detriment and evaluated for the use in numerous civil engineering areas. [Meral et al. 2011] investigated the laser scanner data reliability on bridge inspection projects by using point cloud, a 3D model of the bridge is made, dimensions of the pier components of the bridge were measured, and the results were contrasted against design drawing data. All the results and comparisons exposed that the scanned data is reliable in its accuracy showed that an elaborated inspection of the estate of a bridge and other constructions can be made by laser scanning technology that permits analyzing 3D point clouds and reconstructing the surface models of these structures. The main objective of this research is to detect the geometric discrepancies and defects inspection by simplifying the method of information visualization, by registration and compare 
between the "as-built" model gained from 3D laser scanning process and the "designed" model from BrIM, and evaluate the accuracy of terrestrial laser scanners for bridge inspection. [Bosche et al. 2010] suggested an automated way for identification of construction objects, extraction of as-built information from laser scanned data through their registration with 3D models and reported an approach for estimating the as-built model and dimensions of CAD model objects from the scan data of an industrial building's steel structure. [Tang, P. and Akinci et al. 2009] compared two successive scans those are recorded throughout the process to track changes during construction. [Hori et al. 2007] used laser scanner to determine the accuracy of original structural drawings compared with the as-built conditions. [Shih and Wang et al.2004] compared the work process at a construction site with the original construction schedule using point cloud obtained from laser scanner.

\section{Laser Scanning Technology}

3D laser scanning is a relatively new surveying technology that captures the real scenery and translates it into a 3D virtual world. It utilizes light detection and ranging to produce accurate 3D representation of objects. The result of a scan produces a collection of points in space, commonly known as "point clouds" which can be processed and combined into accurate 3D models [Su et al., 2006]. Terrestrial laser scanners scan the surface of an object by getting coordinates in just few seconds, probably with color information i.e. RGB (Red, Green, and Blue) varying according to the function of the scanner and the distance between the scanner and the object. The point cloud data obtained by the scanning method could be in an XYZIRGB (X, Y, Z coordinate, return Intensity, and Red, Green, Blue color values) format if color data is available.

\section{Methodology}

The mentioned system was supposed to include most of the necessary concerns as shown in Figure (1). The system begun with bridge object through laser scanning process to create point cloud and send the raw data to Cyclone software in order to register four different points clouds into one coordinate system. Proceed to transfer them to AutoCAD software to develop the 3D as-built model. Meanwhile, the designed CAD model was transferred to the same software to apply comparison between them. Finally, geometric discordances were detected as defects.

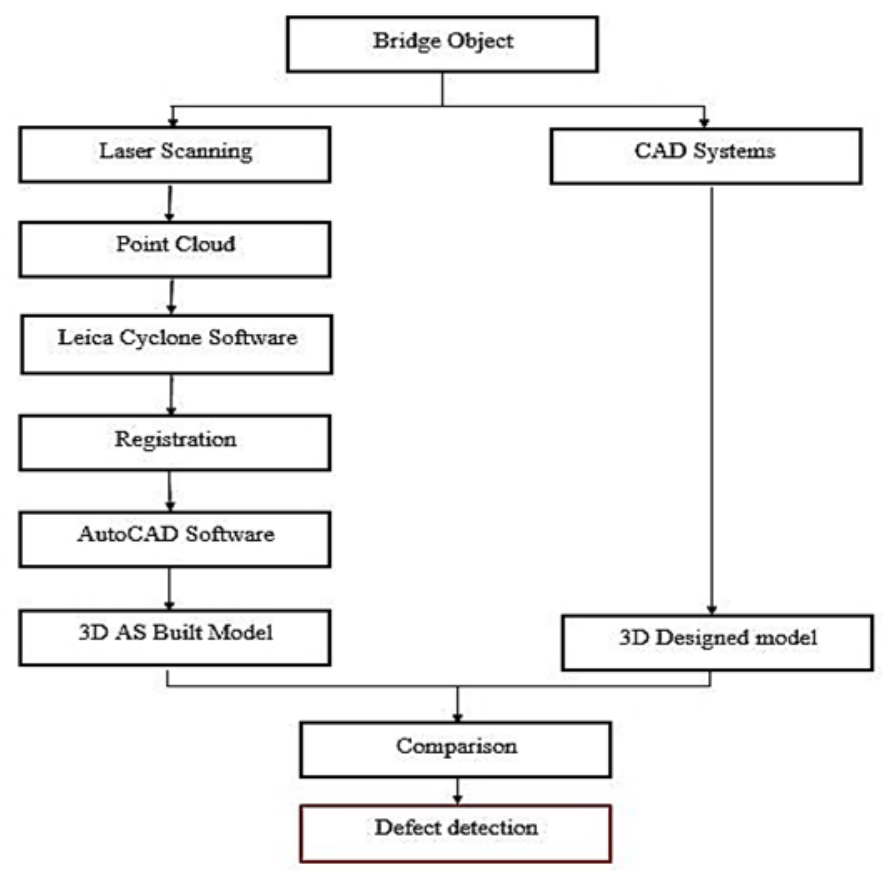

Figure (1): Research Plan

\section{Equipment and Software}

Leica scanstation P30 was available and suitable to perform the practical work of the study which is a time-of-flight system. It operates at a wavelength of 1550 $\mathrm{nm}$. The scanner applied in this thesis is able to get millions of points per a second. More precise details specifications of the Laser scanner system are shown in Table (1).

Table (1): Specifications of Leica scanstation P30

\begin{tabular}{|l|l|}
\hline System Accuracy & $1.2 \mathrm{~mm}+10 \mathrm{ppm}$ over full range \\
\hline Range accuracy & 8 " horizontal; 8 " vertical \\
\hline Angular accuracy & $3 \mathrm{~mm}$ at $50 \mathrm{~m} ; 6 \mathrm{~mm}$ at $100 \mathrm{~m}$ \\
\hline 3D position accuracy & $\begin{array}{l}\text { Minimum range }(0.4 \mathrm{~m}) \\
\text { Distance Measurement System }\end{array}$ \\
\hline Range and reflectivity & Maximum range at reflectivity (120m) \\
\hline
\end{tabular}

3.1 Evaluate the accuracy of terrestrial laser scanners

The distance to a target will affect the accuracy of a distance measurement as well as the reflectivity of the surface of the object being scanned. The new Leica scanstation P30 has a reported single distance accuracy of $1.2 \mathrm{~mm}+10 \mathrm{ppm}$ over full range. The angle accuracy is 8 " horizontal; 8 " vertical and the overall position accuracy is $3 \mathrm{~mm}$ in the 1 to 50 -meter range and $6 \mathrm{~mm}$ to the $100 \mathrm{~mm}$ range. To evaluate the accuracy of laser scanner distances and coordinates were measured by total station and terrestrial laser scanner then making comparison between them. Firstly, a test has been conducted to evaluate the accuracy of terrestrial laser scanners coordinates., Total station (Topcon MS1A) was used to observe the coordinates of four points using the direct reflector with high accuracy as shown in table (2), then the same point was scanned using terrestrial laser scanner (Leica P30). 
Citation: Ayman Elshehaby, Khaled Zaky, Farag Bastawy and Hany Abd Elmaksoud Detection and Evaluation of Surface Defects in Bridges by Terrestrial Laser Scanning. Australian Journal of Basic and Applied Sciences, 12(7): 139-147. DOI: 10.22587/ajbas.2018.12.7.21.

Table (2): Specifications of total station (Topcon MS1A)

\begin{tabular}{|l|l|}
\hline \multicolumn{2}{|l|}{ Distance Measurement } \\
\hline Measuring range & 1.3 to $300 \mathrm{~m}$ \\
\hline Reflective sheet & 1.3 to $3,500 \mathrm{~m}$ \\
One prism & $\pm(1+1 \mathrm{ppm} \times \mathrm{D}) \mathrm{mm}$ \\
\hline Accuracy (Standard Deviation based on ISO 17123-4) \\
\hline Prism & $\pm(1+1 \mathrm{ppm} \times \mathrm{D}) \mathrm{mm}$ \\
\hline Reflective sheet & $1 " / 0.3$ mgon \\
\hline Angle Measurement & \\
\hline Angle accuracy & \\
\hline
\end{tabular}

The coordinates shown in Table (3) represent the points extracted from the 3D model created by Leica Cyclone software using the single point pick function, and the same point which observed by total station as a reference and the difference between them.

Table (3): The differences between the obtained coordinates from Leica scanstation p30 and Total station (Topcon MS1A)

\begin{tabular}{|c|c|c|c|c|c|c|c|c|c|}
\cline { 2 - 10 } \multicolumn{1}{c|}{} & \multicolumn{3}{c|}{ Total station } & \multicolumn{3}{c|}{ 3D Laser Scanner } & \multicolumn{3}{c|}{ Difference } \\
\hline St & Easting & Northing & Elevation & Easting & Northing & Elevation & Delta E & Delta N & Delta Z \\
\hline 1 & 807714.472 & 649704.536 & 181.369 & 807714.479 & 649704.540 & 181.362 & -0.007 & -0.004 & 0.007 \\
\hline 2 & 807739.521 & 649692.862 & 180.619 & 807739.526 & 649692.859 & 180.627 & -0.005 & 0.003 & -0.008 \\
\hline 3 & 807648.036 & 649713.043 & 180.650 & 807648.031 & 649713.036 & 180.656 & 0.005 & 0.007 & -0.006 \\
\hline 4 & 807672.286 & 649724.694 & 181.365 & 807672.292 & 649724.689 & 181.357 & -0.006 & 0.005 & 0.008 \\
\hline
\end{tabular}

\subsubsection{Accuracy Analysis}

After the comparison between the obtained coordinates from Leica scanstation P30 and Total station (Topcon MS1A) the results showed that the terrestrial laser scanner coordinates were very closely with Total station coordinates with an average error of $6 \mathrm{~mm}$ in easting, $5 \mathrm{~mm}$ in northing and a maximum error of $8 \mathrm{~mm}$ in elevation. The test showed that accuracy of $( \pm 8 \mathrm{~mm} @ 120 \mathrm{~m})$ is acceptance according to it is designed from the manufacturer. Secondly, a test has been conducted to evaluate the accuracy of laser scanner distances. This test is to compare the distances measured from the scanner to the standard target plate mounted with a white paper against the known distances ranging every 20 meter from $0 \mathrm{~m}$ to $120 \mathrm{~m}$ as shown in table (4).

Table (4): Test on Distance Measurement of Leica scanstation P30

\begin{tabular}{|c|c|c|c|}
\hline $\begin{array}{c}\text { Interval } \\
(\mathbf{m})\end{array}$ & $\begin{array}{c}\text { Known Distance } \\
\mathbf{R 0}(\mathbf{m})\end{array}$ & $\begin{array}{c}\text { Measured Distance } \\
\mathbf{R m}(\mathbf{m})\end{array}$ & $\begin{array}{c}\text { Difference } \\
\mathbf{R 0}-\mathbf{R m}(\mathbf{m m})\end{array}$ \\
\hline $0-20$ & 20.000 & 19.999 & +1 \\
\hline $0-40$ & 40.000 & 40.001 & -1 \\
\hline $0-60$ & 60.001 & 59.999 & +2 \\
\hline $0-80$ & 79.999 & 79.997 & +2 \\
\hline $0-100$ & 99.999 & 100.001 & -2 \\
\hline $0-120$ & 120.001 & 119.999 & +2 \\
\hline
\end{tabular}

The results in Table (4) showed that the expected accuracy of $(1.2 \mathrm{~mm}+10 \mathrm{ppm}$ over full range) were very closely as it is designed from the manufacturer. In addition to the accuracy of scanner and processing tools, all scan positions were tied to a horizontal and vertical control networks which were established using GPS to achieve the greatest accuracy during georeferencing and registering the LIDAR data. Figure (2) shows an aerial view of the test area with the control setup.

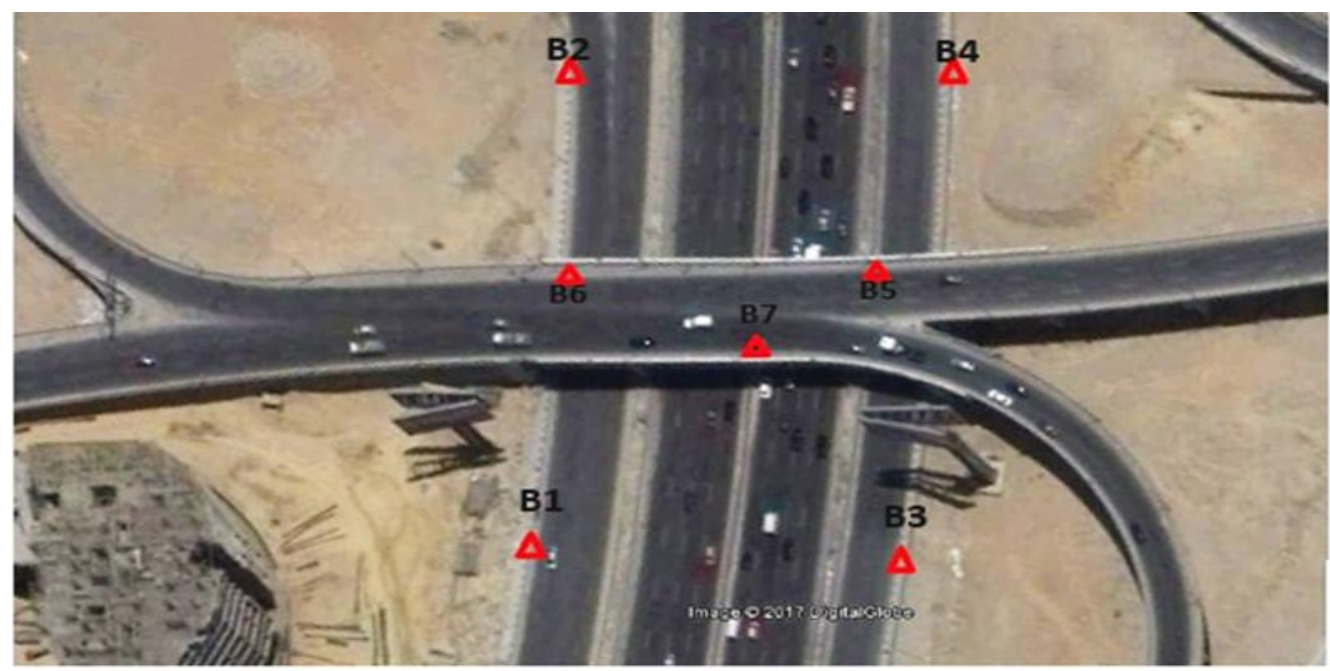

Figure (2): Test area with location of control points 
Citation: Ayman Elshehaby, Khaled Zaky, Farag Bastawy and Hany Abd Elmaksoud Detection and Evaluation of Surface Defects in Bridges by Terrestrial Laser Scanning. Australian Journal of Basic and Applied Sciences, 12(7): 139-147. DOI: 10.22587/ajbas.2018.12.7.21.

The detailed coordinate information of control points obtained by GPS is recorded in table (5).

Table (5): Coordinates of control points obtained by GPS

\begin{tabular}{|c|c|c|c|}
\hline \multicolumn{3}{|c|}{ ETM Coordinates of control points } \\
\hline Point-id & Easting & Northing & Geodetic Height \\
\hline B1 & 649638.8799 & 807714.4723 & 172.4275 \\
\hline B2 & 649752.1490 & 807739.5215 & 176.7047 \\
\hline B3 & 649663.0829 & 807648.0363 & 175.1972 \\
\hline B4 & 649766.7467 & 807672.2866 & 184.7191 \\
\hline B5 & 649728.5408 & 807659.9023 & 182.8985 \\
\hline B6 & 649705.0450 & 807729.2222 & 184.1908 \\
\hline B7 & 649698.3901 & 807693.9887 & \\
\hline
\end{tabular}

Control points are used to adjust, geo-reference, and combine different scans together in the registration step. Targets should be placed at the recommended optimal distance from the scanner according to the scanners manual. Scanning actions begins once equipments were set-up. After, scanning action starts, the scanner should not be moved during the scanning process as it may cause data loss. This process repeated four times at four different scan locations to achieve a complete coverage to produce a point cloud. Registration is the process of the combination of 3D data gained from scan worlds into one 3D system. The data collected from four different scan locations are combined and registered into one common coordinates system. Through 3D registration, 3D model of the bridge in addition to its surroundings is created. In this thesis Cyclone software used to process point cloud information into a 3D system, (see figure 3).

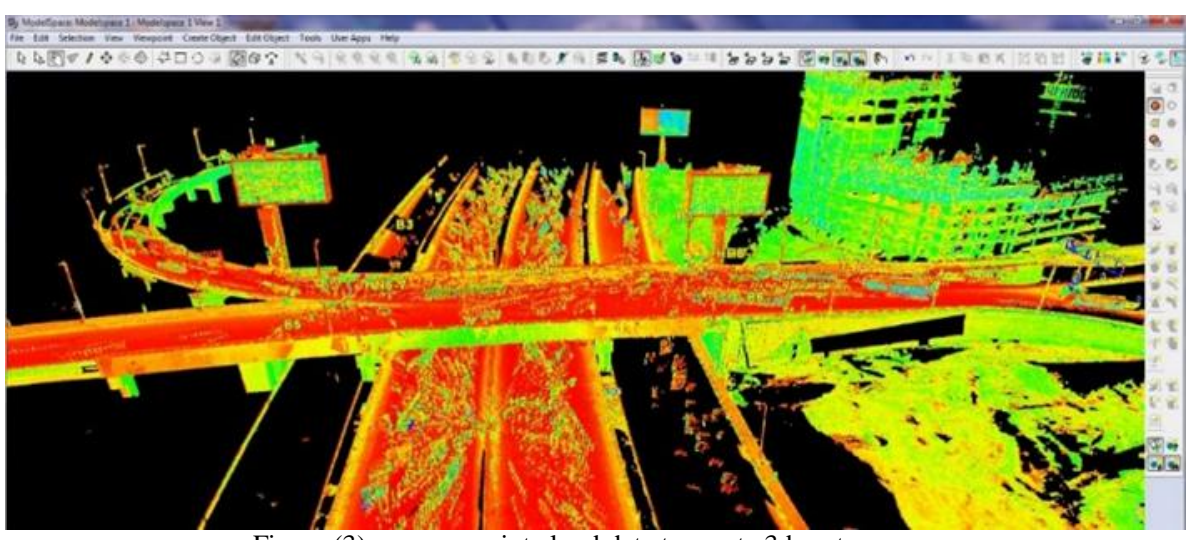

Figure (3): process point cloud data to create $3 \mathrm{~d}$ system

\section{Creation of 3D Model}

The 3D model consists of bridge girders, bracings, pier caps, pier columns, abutments, and superstructure of the bridge. There are millions of points in one scan used in 3D creation process. Depending on surfaces, different types of geometrical shapes can be assigned manually or automatically. For this process, Cyclone has a surface fitting option where it can fit basic geometrical shapes with the selected points in point clouds automatically. It recognizes what kind of prismatic object surface looks like, identifies the surface, creates a 3D shape and fits it to the surface. This method is fairly accurate as long as the selected points are segmented and distributed in the surface properly. Different surfaces in different shapes can be chosen manually, identified and created by Cyclone automatically. First, select several points on a surface. Based on X, Y, Z, components of the points on the same surface, the software can identify what kind of geometrical shape the surface has. It may be cylindrical, conic, cubic prismatic or it can be an irregular surface. Then the 3D Model of the entire bridge was created as shown in figure (4).
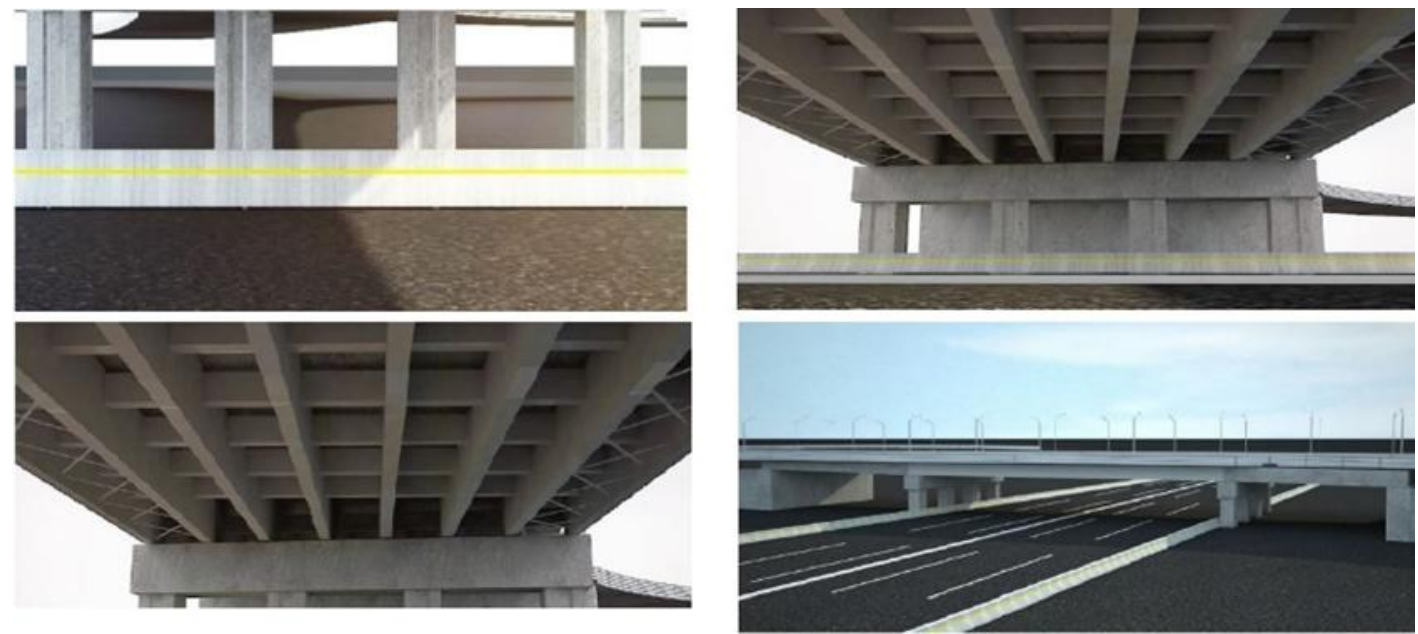

Figure (4): 3D Model of the entire bridge 
Citation: Ayman Elshehaby, Khaled Zaky, Farag Bastawy and Hany Abd Elmaksoud Detection and Evaluation of Surface Defects in Bridges by Terrestrial Laser Scanning. Australian Journal of Basic and Applied Sciences, 12(7): 139-147. DOI: 10.22587/ajbas.2018.12.7.21.

The functional objectives of bridge evaluation programs using terrestrial laser scanning are to detect and quantify defects, measuring bridge clearance, deformation, and evaluation of surface defects. After the processes of data acquisition and model creation, precise geometrical data can be derived. Then measure and evaluate the virtual structure model and give out the inspection results.

\subsection{Geometric Results and Analysis}

The first damage detection algorithm is based on registration and comparison between the as-built model from 3D laser scanning and the designed model from bridge information model to detect the geometric discrepancies and defects. To clarify the dimension of comparison, naming each pier and abutment as they are named in the initial structural design of the bridge (1E and $1 \mathrm{~W}$ ) as presented in figure (5).
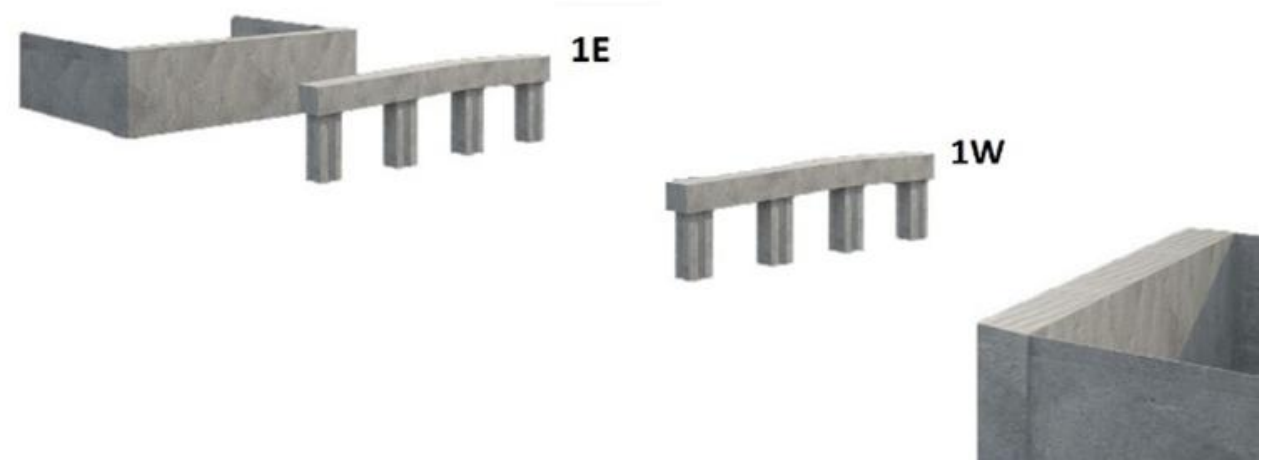

Figure (5): AutoCAD 3D Model of the Bridge shows the name of the piers

By using AutoCAD software and the initial structural design of the bridge, the dimensions of all components of the bridge are measured. Then, by using VisionLidar software, scanned data dimensions of the bridge are measured as shown in figure (6), then compare between them.

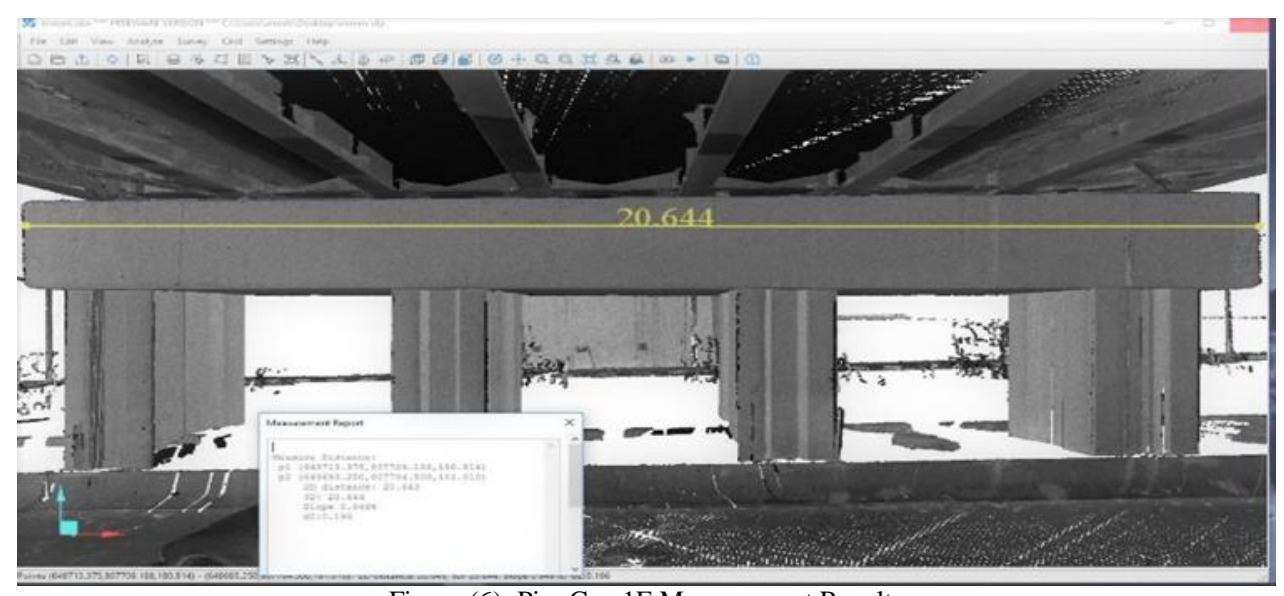

Figure (6): Pier Cap 1E Measurement Results

Table (6) shows the results and error ratio of the comparison between designed dimension and as-built dimension of pier cap 1E.

Table (6): Pier Cap 1E Measurement Results and Error Ratio

\begin{tabular}{|c|c|c|c|}
\hline Pier Cap 1E Data & Top length $(\mathrm{m})$ & Depth $(\mathrm{m})$ & Width $(\mathrm{m})$ \\
\hline Designed dimension & 20.65 & 2.00 & 2.25 \\
\hline As-built dimension & 20.77 & 1.928 & 2.222 \\
\hline Difference & 0.120 & -0.072 & -0.028 \\
\hline Error Ratio (\%) & 0.590 & -3.600 & -1.240 \\
\hline
\end{tabular}

Table (7) shows the column dimension measurement results and error ratio of the comparison between scanned data and data from drawings.

Table (7): Column Dimension Measurement Results and Error Ratio

\begin{tabular}{|l|l|l|l|l|}
\hline Column Name & $\begin{array}{l}\text { Data from } \\
\text { design }\end{array}$ & $\begin{array}{l}\text { Scanned } \\
\text { Data }\end{array}$ & $\begin{array}{l}\text { Difference } \\
(\mathrm{m})\end{array}$ & $\begin{array}{l}\text { Error Ratio } \\
(\%)\end{array}$ \\
\hline Pier column 1 (1 E) & 1.75 & 1.632 & -0.118 & -6.74 \\
\hline Pier column 2 (1 E) & 1.75 & 1.639 & -0.111 & -6.34 \\
\hline Pier column 3 (1 E) & 1.75 & 1.636 & -0.114 & -6.51 \\
\hline Pier column 4 (1 E) & 1.75 & 1.631 & -0.119 & -6.8 \\
\hline Pier column 5 (1 W) & 1.75 & 1.633 & -0.117 & -6.69 \\
\hline Pier column 6 (1 W) & 1.75 & 1.633 & -0.117 & -6.69 \\
\hline Pier column 7 (1 W) & 1.75 & 1.635 & -0.115 & -6.57 \\
\hline Pier column 8 (1 W) & 1.75 & 1.639 & -0.111 & -6.34 \\
\hline
\end{tabular}


Citation: Ayman Elshehaby, Khaled Zaky, Farag Bastawy and Hany Abd Elmaksoud Detection and Evaluation of Surface Defects in Bridges by Terrestrial Laser Scanning. Australian Journal of Basic and Applied Sciences, 12(7): 139-147. DOI: 10.22587/ajbas.2018.12.7.21.

Table (8) shows the column distance measurement results and error ratio of the comparison between scanned data and data from drawings.

Table (8): Column Distance Measurement Results and Error Ratio

\begin{tabular}{|c|c|c|c|c|}
\hline & $\begin{array}{l}\text { Data from } \\
\text { Drawings }\end{array}$ & $\begin{array}{l}\text { Scanned } \\
\text { Data }\end{array}$ & $\begin{array}{l}\text { Difference } \\
(\mathrm{m})\end{array}$ & $\begin{array}{l}\text { Error Ratio } \\
\quad(\%)\end{array}$ \\
\hline $\begin{array}{l}\text { Pier column } 1 \text { (1 E) and Pier column } 2 \\
\text { (1 E) }\end{array}$ & 6.00 & 6.010 & 0.010 & 0.17 \\
\hline $\begin{array}{l}\text { Pier column } 2 \text { (1 E) and Pier column } 3 \text { (1 } \\
\text { E) }\end{array}$ & 6.00 & 6.034 & 0.034 & 0.57 \\
\hline $\begin{array}{c}\text { Pier column } 3(1 \mathrm{E}) \\
\text { And Pier column } 4(1 \mathrm{E})\end{array}$ & 6.00 & 6.013 & 0.013 & 0.22 \\
\hline $\begin{array}{c}\text { Pier column } 1(1 \mathrm{~W}) \\
\text { And Pier column } 2(1 \mathrm{~W})\end{array}$ & 6.00 & 6.016 & 0.016 & 0.27 \\
\hline $\begin{array}{c}\text { Pier column } 2(1 \mathrm{~W}) \\
\text { And Pier column } 3(1 \mathrm{~W})\end{array}$ & 6.00 & 6.035 & 0.035 & 0.58 \\
\hline $\begin{array}{c}\text { Pier column } 3(1 \mathrm{~W}) \\
\text { And Pier column } 4(1 \mathrm{~W})\end{array}$ & 6.00 & 6.032 & 0.032 & 0.533 \\
\hline
\end{tabular}

\subsubsection{Analysis of Results}

The Comparison results between the design and scanned data show that:

1.The dimension of the pier columns in as-built model was less than that of the designed model by $10 \mathrm{~cm}$, and this is not a deformation but it's a redesign of that pier column which is not stated in the design drawing data and this shows the importance of observing the bridge after construction.

2.The observation showed that there was a different between the as-built dimension of the pier cap and designed model.

\subsection{Minimum Vertical Clearance}

The vertical clearance of a bridge over a highway is important in preventing oversized vehicles from hitting the bridge. It is usually calculated with the help of surveying equipment as total stations and leveling rods. Normally, measurements are made at different areas in order to establish the minimum vertical clearance under the bridge. This action is time and labor consuming. This research provides a highly accurate measurement of the vertical bridge clearance by using laser scanning technology. The whole bridge data is saved in point clouds data and clearance measurements can be obtained in the office with high accuracy by calculating the distance between the road surface and lower beam of the bridge at several locations using Leica Cyclone software as shown in figure (7).

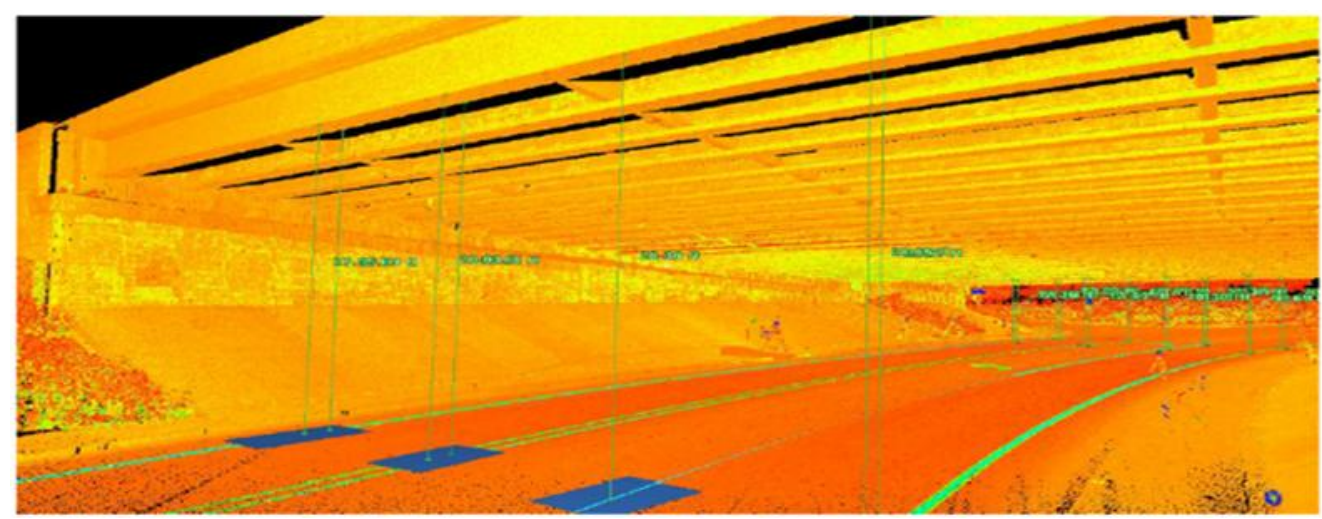

Figure (7): Clearance values measured from point cloud to roadway surface

Multiple clearances were measured from the pavement to the lower beam of the bridge to define the minimum vertical clearance, after the clearance is measured, a vertical clearance report of the specific bridge is generated and the result was compared to the design drawing data as shown in table (9).

Table (9): Vertical Clearance Measurement Results and Error Ratio

\begin{tabular}{|c|c|c|c|c|}
\hline Point & $\begin{array}{c}\text { Data from } \\
\text { Drawings }\end{array}$ & $\begin{array}{c}\text { Scanned } \\
\text { Data }\end{array}$ & $\begin{array}{c}\text { Difference } \\
(\mathrm{m})\end{array}$ & $\begin{array}{c}\text { Error Ratio } \\
(\%)\end{array}$ \\
\hline 1 & 6.00 & 5.972 & -0.028 & -0.46 \\
\hline 2 & 6.00 & 5.976 & -0.024 & -0.40 \\
\hline 3 & 6.00 & 6.010 & 0.010 & 0.17 \\
\hline 4 & 6.00 & 6.008 & 0.008 & 0.13 \\
\hline 5 & 6.00 & 6.012 & 0.012 & 0.20 \\
\hline 6 & 6.00 & 5.974 & -0.026 & -0.43 \\
\hline
\end{tabular}

The system outcome can provide bridge vertical clearance information at multiple points under a bridge with accuracy in the order of millimeters. The display of clearance change over the entire bridge coverage area can be useful to assess damages and help engineers to device bridge improvement planning. Temporal analysis of clearance changes can also be performed for monitoring bridge abutment settlement or the increase in road pavement thickness

\subsection{Crack Measurements}

The objective is to determine type, number, width and length of the cracks on the structural surface shows the earliest degradation level and carrying capacity of concrete. The crack width was measured each three meters along the bridges using laser scanner as shown in figure (8). 


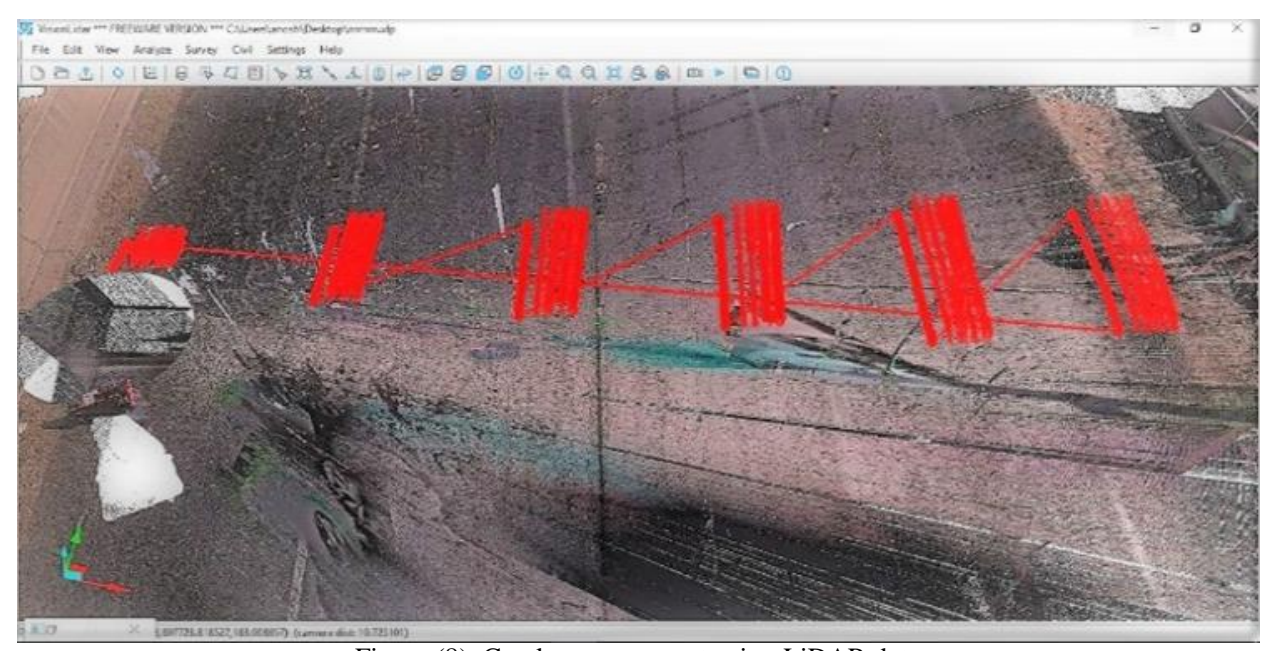

Figure (8): Crack measurement using LiDAR data

The depth could not measure by laser scanner because the laser beam can't penetrate the crack to compute its depth. So that, a Vernier was used to measure the depth. Table (10) shows the results obtained from laser scanner and Vernier for six cracks.

Table (10): Concrete crack width and depth

\begin{tabular}{|c|c|c|c|}
\hline Crack-id & Distance & Crack width from scanner $(\mathrm{cm})$ & Crack depth from Vernier (cm) \\
\hline C-1 & 0 & 1.2 & 0.6 \\
\hline C-2 & 3 & 0.4 & 1.510 \\
\hline C-3 & 6 & 1.9 & 1.510 \\
\hline C-4 & 9 & 1.2 & 1.925 \\
\hline C-5 & 12 & 1.4 & 2.745 \\
\hline C-6 & 15 & 0.9 & 1.332 \\
\hline
\end{tabular}

These results are compared with the Concrete crack width guidelines and classified as Medium corresponding to the value that appears in table (11) [ECP-2008]. So that the terrestrial laser scanners' data accuracy is reliable for measuring the Concrete crack width.

Table (11): Concrete crack width guidelines [ECP-2008]

\begin{tabular}{|c|c|}
\hline Classification & Metric \\
\hline Structural Narrow & $<1.0 \mathrm{~cm}$ \\
\hline Medium & $1.0 \mathrm{~cm}$ to $2.5 \mathrm{~cm}$ \\
\hline Wide & $>2.5 \mathrm{~cm}$ \\
\hline
\end{tabular}

\subsection{Evaluation of Surface Defects}

TLS has also been used to detect surface deterioration (e.g. biological crust, cracking, spalling or volume loss). It is easy to get the relative position of a defective area on the bridge from the scan, which is difficult to be achieved using local digital images. An experimental work is carried out to confirm a method for evaluating surface defects through a case study in the pier cap surface as shown in figure (9). This is performed by picking a lot of scan points on the pier cap to create a surface. Then compare this points with their corresponding points created from the designed surface. Most of the critical bridge components have flat surfaces, such as girders, decks and some of the bridge abutments. The coordinate value differences between the selected scan points and the designed surface are used to decide whether a scan point belongs to the damaged part. So, all surface points are moved to make the flat plane vertical to "Z" coordinate (out of plane). Then, the deviation between the scan points and the design surface (D) can be easily obtained as: $D=|Z P-Z \mathrm{R}|$ where $Z P$ is the $\mathrm{Z}$ coordinates value of the selected points, and $Z R$ is the $\mathrm{Z}$ coordinate value of the designed surface. 
Citation: Ayman Elshehaby, Khaled Zaky, Farag Bastawy and Hany Abd Elmaksoud Detection and Evaluation of Surface Defects in Bridges by Terrestrial Laser Scanning. Australian Journal of Basic and Applied Sciences, 12(7): 139-147. DOI: 10.22587/ajbas.2018.12.7.21.

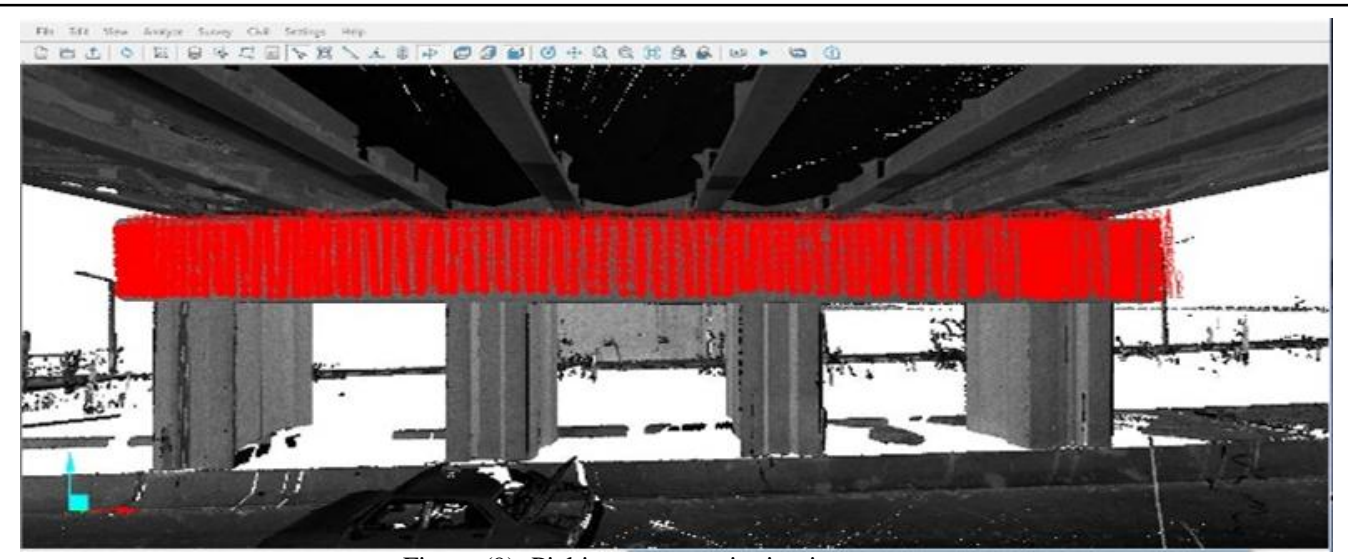

Figure (9): Picking a scan point in pier cap

Comparison of the design surface data with their corresponding scanned data showed that there are surface defects. The max difference rise is $0.081 \mathrm{~m}$ and the minimum difference fall is $-0.051 \mathrm{~m}$ in surface shown in figure (9). Also, the software of 3DReshaper can be used if the defects of a bridge are studied periodically, the mass loss rate can be determined automatically. Then, the data can be used to generate or update the deterioration rate prediction model.

\subsection{Cross Section}

The Cross section profiles in where in the collected data could be easily done. by choosing two points across a line then the cross section will be produced as shown in figure (10).

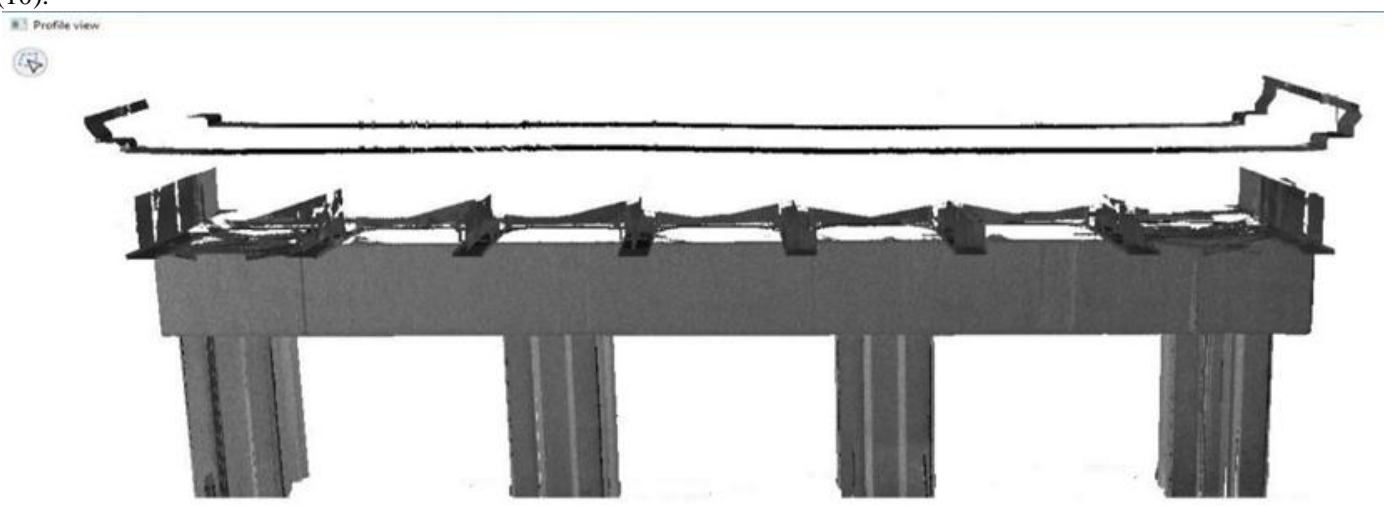

Figure (10): bridge cross section

\section{Conclusion}

From the research conducted herein, the following conclusions are described as follows:

1. The proposed methodologies demonstrate that 3D laser scanner can be useful tools for determining bridge clearances of the bridge, evaluation of surface defects, and Crack Measurement

2. The dimension of the pier columns in as-built model was less than that of the designed model by $10 \mathrm{~cm}$, and this is not a deformation but it's a redesign of that pier column which is not stated in the design drawing data and this shows the importance of observing the bridge after construction.

3. The observation showed that there was a different between the as-built dimension of the pier cap and designed model.

4. The observation showed that there was a different between the as-built surface of the pier cap and designed model.

5. The results of crack measurements are compared with the Concrete crack width guidelines and classified as Medium.

6. The display of clearance change over the entire bridge coverage area can be useful to assess damages and help engineers to device bridge improvement planning.

7. Observation showed that the instrument is observing 15 million points per square meter with distance 20 meter.

8. Cross section profiles in where in the collected data could be easily done.

\section{Recommendations for future studies}

The scope of the current research and would require additional study and/or testing to fully investigate. Suggestions for future work include the following

1. Results showed be evaluated for being significant or not by specialized civil engineer.

2. Periodical observation is recommended to observe deformations.

3. Temporal analysis of clearance changes can also be performed for monitoring bridge abutment settlement or the increase in road pavement thickness.

4. Periodical observation is recommended to observe cracks.

5. The observed crack on the surface of the bridge should be periodically observed by installing the instrument above the crack to be able to get an accurate measurement of the crack width and depth.

6. More studies should be done to evaluation and enhance the automatic image registration.

7. Another study that can be conducted in order to broaden the use of laser scanners is the integration of laser scanners with ground penetrating radar systems. As we know GPR systems are used to investigate the underground, to receive the 3D fusion data. GPR allows detailed images of sub-surface to be seen in 
real time. With the scanned data from scanners, 3D model of subsurface can be created. This future study can be very beneficial for geotechnical or archeological research.

8. Thus, another recommendation is to measure the bridge components dimensions by using a total station. After we received the measurements from the total station, our measurement comparisons can be more accurate.

9. Edge loss of scanned object is another aspect; which researchers should focus on. Mixed pixels can cause significant errors in the measurements of object dimensions in laser scanned data. Field experiments show that in most cases, the model substantially reduces the measurement percentages, by over $80 \%$ [Tang, et. al. 2009]. Some algorithms can be developed which automatically detect the edge loss ratio, moderate two different measures from the same point and give more accurate results. Also, edge detection and advance filtering software related to laser scanners can be created. In this case, before the registration of point clouds, the developed software can be used to detect the edge loss and to clear the edge noises to give more accurate results.

\section{REFERENCES}

Abdel hafiz, A., (2014)., "Integrating Laser Scanning”. Digital Photogrammetry, and Thermography Civil Engineering Department, Faculty of Engineering, Assiut University, Egypt.

Abdelhafiz, A., (2009)., "Integrating Digital Photogrammetry and Terrestrial Laser Scanning”. (Ph.D. thesis). Institute for Geodesy and Photogrammetry, Technical University Braunschweig, Germany (online on Deutsche Geodaetische Kommission (DGK), Muenchen).

Akinci, B., Boukamp, F., Gordon, C., Huber, D., Lyons, C., Park, K., (2006). "A formalism for utilization of sensor systems and integrated project models for active construction quality control". Autom. Constr. 15 (2), 124-138.

Arditi, D., Gunaydin, H.M., (1997). “Total quality management in the construction process”. Int. J. Project Manage. 15 (4), $235-243$.

Bosché, F., (2010). "Automated Recognition of 3D CAD Model Objects in Laser Scans and Calculation of As-built Dimensions for Dimensional Compliance Control in Construction". Advanced Engineering Informatics, 24(1), 107-118

(ECP), (2008). "Egyptian Code of Practice for Urban and Rural Roads: Road materials and their tests". The Ministry of Housing, Utilities and Urban Communities, Egypt.

Gairns, C., (2008). "Development of a Semi-Automated System for Structural Deformation Monitoring using a Reflector-Less Total Station”. (M.Sc. thesis). University of New Brunswick, Canada

Ismaiel, H.A.H., Makhloof, A.A., Mahmoud, A.A., Galal, A.A., (2013). "Monitoring system of cracks along Qena-Safaga Road Using TotalStation, Eastern Desert". Egypt. In: Conference Program and Abstracts, the Second Symposium on the Geological Resources in the Tethys Realm, 5-8 January, Aswan, Egypt.

Kim, H. Son, C. Kim., (2013). "Automated construction progress measurement using a 4D building information model and 3D data". Autom. Constr. 31 (2013) $75-82$

Liu, W., Chen, S., and Hasuer, E., (2012). "Bridge Clearance Evaluation Based on Terrestrial LIDAR Scan”. J. Perform. Constr. Facil., 26(4), $469-477$.

Meral, C., (2011). "Evaluation of Laser Scanning Technology for Bridge Inspection". Drexel University, Civil Engineering. Philadelphia: Drexel University.

Nahangi, M., Safa, M., Shahi, A., Haas, T., (2014). "Automated Registration of 3D Point Clouds with 3D CAD Models for Remote Assessment of Staged Fabrication". Construction Research Congress,_ASCE.

P. Tang, B. Akinci., (2012). "Formalization of workflows for extracting bridge surveying goals from laser-scanned data". Automation in Construction 22 (2012) 306-319.

Sedek, M, and Serwa, A., (2015). "Development of new system for detection of bridges construction defects using terrestrial laser remote sensing technology". The Egyptian Journal of Remote Sensing and Space Sciences, PP. 1- 17

Shih, N.-J. And Wang, P.-H., (2004). "Point-cloud-based Comparison between Construction Schedule and As-built Progress: Long-range Three-dimensional Laser Scanner's Approach". Journal of Architectural Engineering, 10(3), 98-102.

Tang, P., Akinci, B. and Huber, D., (2009). "Quantification of edge loss of laser scanned data at spatial discontinuities". Department of Civil and Environmental Engineering, Carnegie Mellon University, Pittsburg, PA, USA.

Tzedaki, V., \& Kamara, J. M., (2013). “Capturing As-Built Information for a BIM Environment Using 3D Laser Scanner”. A Process Model. In AEI 2013@ Building Solutions for Architectural Engineering (pp. 486-495). ASCE.

Wanqiu L, Shen-En C., (2012). "Reliability Analysis of 3D LiDAR Bridge Evaluation". Nondestructive Characterization for Composite Material, Aerospace Engineering, Civillnfrastructure, and Homeland Security [Internet]. [Cited 2012 February 20, 2012];7983:13.

Yoshiki HORI, Osamu Ajioka, Asami Hanghai C., (2007). "Laser Scanning in Pompeian City wall A comparative study of accuracy of the drawings from 1930s to 1940s,3D-Arch'2007 3D Virtual Reconstruction and Visualization of Complex Architectures".2007.07 